\title{
Corrigendum
}

\section{Activity performance and upper extremity function in cervical spinal cord injury patients according to the Klein-Bell ADL Scale}

\author{
A Dahlgren, A-K Karlsson, Å Lundgren-Nilsson, J Fridén and L Claesson
}

Spinal Cord (2007) 45, 531; doi:10.1038/sj.sc.3102032

Correction to: Spinal Cord (2007) 45, 475-484.

Since the publication of the above article, the authors have noticed that a sentence in the acknowledgements had been omitted. The full acknowledgement section is shown below:

\section{Acknowledgements}

We thank Anna Ekman for valuable help with statistics. This study was supported by grants from the Norr-
backa-Eugenia Foundation, The Swedish Association of Survivors of Traffic Accidents and Polio foundation (RTP), The Foundation of Sunnerdahls Handicap Fund, The Swedish National Association for Disabled Children and Young People (RBU), The Capio Foundation, The Council of Research and Development of Gothenburg and Southern Bohuslan, Swedish Research Council (VRK2002-27-VX-14318-01A).

The authors would like to apologise for this error. 